\title{
PRINCIPIOS DEMOCRÁTICOS EN ATENAS Y EN LA REPÚBLICA ROMANA
}

\section{DEMOCRATIC PRINCIPLES IN ATHENS AND THE ROMAN REPUBLIC}

\author{
PROFa DR ${ }^{a}$ ALICIA VALMAÑA OCHAÍTA \\ Profesora Titular de Derecho Romano Universidad de Castilla-La Mancha
}

Fecha de recepción: 19 de octubre de 2009

Fecha de aprobación: 3 de marzo de 2010

\section{Resumen:}

Atenas crea la demokratía y Roma la re publica. Ambos sistemas se sustentan básicamente en las mismas estructuras constitucionales en las que el dêmos o populus participa de la vida política en una relación más o menos estable de equilibrio con los demás órganos de poder (Senado o Areópago y magistraturas). La historia de ambas ciudades será la de la lucha por alcanzar cada vez cotas más altas de presencia y decisión del pueblo en todas las instituciones.

\section{Abstract:}

Athens creates demokratía and Rome the re publica. Both systems are sustained, basically, in the same constitutional structures in which the dêmos or populus 
participate in the political life in a more or less stable relation of balance with the other organs of being able (Senado or Areópago and magistratures). The history of both cities will be that one of the fight to reach, each time, higher levels of presence and decision of the people in all institutions.

\section{Palabras clave:}

Democracia, ciudadanos, órganos constitucionales, principios democráticos, equilibrio de poderes.

\section{Key words:}

Democracy, citizen, constitutional structures, democratic principles, powers balance.

\section{1.- Introducción.}

Cuando se analiza cualquier institución del mundo antiguo, ya sea jurídica o política, resulta siempre difícil alejar ciertos conceptos actuales que por estar tan extendidos pueden condicionar la objetividad de esa mirada retrospectiva; cuánto 


\section{REVISTA VIRTUAL VIA INVENIENDI ET IUDICANDI}

"CAMINO DEL HALLAZGO Y DEL JUICIO"

http://viei.usta.edu.co/ E-MAIL: revistainveniendi@usantotomas.edu.co

más cuando esos conceptos tienen una carga tan profunda como el de democracia que se halla, además, íntimamente relacionado con otros como los de libertad, igualdad, derechos fundamentales o derechos humanos. Por eso, hablar de democracia en el mundo clásico como punto de partida probablemente suponga un riesgo difícilmente salvable -además de por las generalizaciones ${ }^{1}{ }^{-}$, si no se tienen claras las coordenadas de espacio y tiempo en que se dieron, o pretendemos que se dieran y en segundo lugar, si no somos conscientes de que difícilmente podemos trasladar al mundo clásico el concepto actual de democracia, al menos en su totalidad ${ }^{2}$.

Por ello puede resultar cuando menos grotesco hablar de democracia en unas sociedades en las que existía la esclavitud o la mujer no participaba en la vida pública o donde la riqueza condicionaba la composición y, en consecuencia, la participación a efectos reales de los ciudadanos en una asamblea. Desde esta perspectiva, el debate acerca de la existencia de un sistema democrático en determinados momentos históricos no debería quizá ni plantearse.

Pero tampoco en nuestros días el concepto de democracia es un concepto unívoco; sólo tenemos que pensar en los distintos modelos democráticos que

\footnotetext{
${ }^{1}$ Sobre generalizaciones e historiadores (Finley M. I., 1977, págs. 91-113).

2 "Cuando empleamos la misma palabra llegamos a la conclusión errónea de creer que nos estamos refiriendo a la misma cosa o a alguna similar. Sin embargo, en el caso de la "democracia" esto significa pasar por alto más de dos mil años de cambio" (Sartori, Teoría de la Democracia. 2. Los problemas clásicos, 1988, pág. 343). Igualmente, sobre el uso de los conceptos en general - también el de democracia- (Lucca, 2006, pág. 73).
} 


\section{REVISTA VIRTUAL VIA INVENIENDI ET IUDICANDI}

"CAMINO DEL HALLAZGO Y DEL JUICIO"

http://viei.usta.edu.co/ E-MAIL: revistainveniendi@usantotomas.edu.co

existen en las sociedades de nuestro entorno donde el simple cambio de régimen electoral establecido puede significar una mayor o menor participación real del ciudadano en el proceso democrático o donde las carencias y deficiencias de todo sistema puede llevarnos a pensar en modelos más o menos democráticos ${ }^{3}$. En cualquier caso, nuestras democracias parten de los principios de "un hombre, un voto", o el "gobierno del pueblo, por el pueblo y para el pueblo" del discurso de Gettysburg, o el principio de la separación de poderes como referentes inexcusables de todo sistema democrático; en definitiva, se basa en la idea de la participación del pueblo en una sociedad/Estado organizado para dotarse libremente de sus gobernantes y de sus leyes ${ }^{4}$.

Pueblo, participación, libertad, gobierno e imperio de la ley son, por tanto, algunas de las ideas sobre las que gira todo sistema democrático y serán las que nosotros intentaremos rastrear en los sistemas políticos clásicos.

En consecuencia, no se pretende en este estudio un análisis detallado de las instituciones políticas concretas de la Atenas democrática y de la República

\footnotetext{
${ }^{3}$ Por no hablar desde el punto de vista de la Teoría de la democracia y los posibles tipos de ésta: participativa, deliberativa, representativa y algunas otras propuestas; como ejemplo reciente, sobre democracia inclusiva (Maíz, 2006).

${ }^{4}$ Evidentemente, la realidad no es tan sencilla. Sobre la fórmula de Lincoln pronunciada en Gettysburg en 1861 (Sartori, Teoría de la democracia. 1. El debate contemporáneo, 1988, pág. 58 y ss). Sobre el concepto de democracia en la actualidad, la bibliografía es abundantísima, por lo que me limito a señalar como mera referencia alguna de las obras de Sartori que probablemente sea uno de los más importantes teóricos de la democracia, (Sartori, La democracia en 30 lecciones, 2009); (Sartori, Teoría de la Democracia. 2. Los problemas clásicos, 1988); (Sartori, ¿Qué es la democracia?, 2007).
} 


\section{REVISTA VIRTUAL VIA INVENIENDI ET IUDICANDI}

"CAMINO DEL HALLAZGO Y DEL JUICIO"

http://viei.usta.edu.co/ E-MAIL: revistainveniendi@usantotomas.edu.co

romana; la bibliografía sobre estas cuestiones es extensa y extraordinaria ${ }^{5}$. Nuestra labor será fijarnos en los principios que subyacen en ambos sistemas en el intento de encontrar ese espíritu democrático del que hablamos.

\section{2.- Paralelismos entre Atenas y Roma: A la búsqueda del principio}

\section{democrático.}

Las diferentes instituciones políticas atenienses y las romanas en su etapa republicana nos ofrecen unas estructuras a menudo similares en cuanto a la organización constitucional de ambas ciudades. Los elementos jurídico-políticos sobre los que pivotan son básicamente los mismos: una asamblea formada por los ancianos o jefes de las familias más poderosas o ex-magistrados que asumen un cargo con carácter vitalicio -Areópago ${ }^{6}$ y Senado-, el pueblo reunido en asamblea

\footnotetext{
${ }^{5}$ Me limito a indicar algunas de las referencias generales en la materia que permitirán al lector interesado profundizar en las instituciones a las que nos referimos a través de las fuentes y bibliografía específica que citan. (Torrent, 2002), (de Martino, 1973) (Arangio-Ruiz, 1980); (Ehrenberg, 1969); (Hignett, 1952); (Rhodes, 2004); (Finley M. I., Estudios sobre historia antigua, 1990) y (Finley M. I., La Grecia primitiva: edad de bronce y era arcaica, 1987).

${ }^{6}$ O Consejo real en la época de la monarquía. Sólo mencionaremos la existencia de diferentes informaciones de los historiadores antiguos acerca de la fecha de creación del Areópago, como lo refiere Plutarco que, al relatar la vida de Solón, se hace eco de la misma: "Los más son de la opinión de que, como dejamos dicho, fue Solón el que estableció el Consejo del Areópago; y parece que está en su favor el no haber hablado ni hecho mención alguna Dracón de los Areopagitas, dirigiendo siempre la palabra a los Efetas en lo que dispuso acerca de los homicidios. Pero la ley octava de la tabla decimotercera de Solón, palabra por palabra, es en esta forma: De los infames todos los que era infames antes de mandar Solón, que sean honrados; fuera de los que por sentencia del Areópago o de los Efetas o del Pritaneo hubiesen sido condenados los reyes sobre muerte, robo o tiranía y hubiesen ido a destierro cuando se publicó esta ley. Esto indica que el consejo del Areópago existía antes del mando y la legislación de Solón. [...] A no ser que hubiese mala escritura o se hubiese cometido elipsis, [...] considérelo cada uno por sî̀. Como se puede observar, Plutarco no se decide por ninguna de las opciones, Vidas paralelas, Solón-Publícola, XIX, 3,5. Parece que el consejo del Areópago existía desde antiguo aunque "posiblemente empezó ahora a llamarse así para diferenciarse del nuevo" (López, 1989, p.46) que sería la Boulé -consejo de los Quinientos- creado por Clístenes. El Consejo de los Cuatrocientos, cuya paternidad es también incierta -Aristóteles lo atribuye a Solón- sería el consejo
} 


\section{REVISTA VIRTUAL VIA INVENIENDI ET IUDICANDI}

"CAMINO DEL HALLAZGO Y DEL JUICIO"

http://viei.usta.edu.co/ E-MAIL: revistainveniendi@usantotomas.edu.co

-Ekklesia y los diferentes Comitia- y por último, Arcontado ${ }^{7}$ y magistraturas, todos ellos en Atenas y Roma, respectivamente.

Dicho de forma más genérica, en ambas ciudades nos encontramos en ciertos momentos de sus respectivas historias con una organización jurídicopolítica que se basa en la existencia de tres elementos fundamentales: un Consejo formado por ex-magistrados, unos magistrados que ejercen el gobierno en el sentido más amplio de la palabra y la asamblea ciudadana ${ }^{8}$.

\section{1.- Atenas.}

Aunque los historiadores antiguos suelen situar el inicio de la democracia a partir de Clístenes ${ }^{9}$, el término “demokratía” utilizado para designar el régimen político imperante nace con las reformas constitucionales de Efialtes y se consolida con Pericles ${ }^{10}$.

En realidad, las reformas de Solón y después Clístenes, son los precedentes sobre los que se asienta la "demokratía” posterior. El estudio histórico de Atenas desde principios del siglo VI a.C. nos muestra un ciclo evolutivo hacia la

intermedio entre los dos citados. No obstante ni la composición, ni las competencias -aunque cada vez vayan sustrayendo más los segundos al Areópago- hacen de los dos consejos, Areópago y consejo de los Cuatrocientos/Quinientos, instituciones equiparables.

${ }^{7}$ Como magistratura principal ateniense.

${ }^{8}$ No obstante, también encontramos diferencias: así, resulta una figura extraña a Roma la del Consejo de los Cuatrocientos y el posterior Consejo de los Quinientos que, desde mi punto de vista, no tienen que ver con la existencia en Roma de diferentes asambleas ciudadanas durante la República ni con la existencia de la asamblea particular plebeya, los concilia plebis tributa, a la que el genio práctico romano llevó a convertir a finales de la República en la asamblea más dinámica legislativamente hablando.

${ }^{9}$ Aristóteles, Constitución de los Atenienses, 23, 1; Heródoto, VI, 131.

${ }^{10}$ En relación a la utilización del término demokratía en tiempos de Efialtes y su contenido, y en general, sobre la historia de la democracia en Atenas, vide Rodríguez Adrados, 1997, pp. 82 y 98. 


\section{REVISTA VIRTUAL VIA INVENIENDI ET IUDICANDI}

"CAMINO DEL HALLAZGO Y DEL JUICIO"

http://viei.usta.edu.co/ E-MAIL: revistainveniendi@usantotomas.edu.co

democracia que no se entendería sin los pasos previos: la "eunomía” de Solón y la "isonomía” de Clístenes significan el gran cambio de mentalidad política dirigida hacia la democracia (Rodríguez Adrados, 1997).

La aportación de Solón ${ }^{11}$ a la historia de la democracia ateniense fue conocida como la eunomía; las "buenas leyes" o "buen gobierno" fue el principio motor sobre el que se asentó la reforma de Solón aunque ésta, si nos fijamos en su contenido, fue principalmente una reforma económica. Rodríguez Adrados (1997, p.36) describe el panorama social gráficamente: "hombres del pueblo empobrecidos y endeudados, a más de con escasos derechos políticos (...), el pueblo enriquecido, pero que seguía con escasos derechos políticos (...) y los nobles empobrecidos, con amplios derechos políticos pero llenos de resentimiento y sufriendo, además, el desprecio del pueblo".

Ante esta situación de bloques claramente enfrentados Solón elabora una legislación que conocemos en parte gracias a sus poemas ${ }^{12}$ que vienen a ser una especie de memorias políticas en las que queda puesto de manifiesto su pensamiento político: él se erige como árbitro entre los bandos que siempre tenderán a imponerse uno por encima del otro. El enfrentamiento, la stasis, es una

\footnotetext{
${ }^{11}$ Accede al arcontado en el año 594 a.C. con el encargo de elaborar nuevas leyes que incluyeran una reforma política en un momento de dominio casi exclusivo del poder por parte de la nobleza y de graves problemas sociales y económicos, (López Melero, 1989).

${ }^{12}$ Recogidos en Aristóteles, Constitución de los atenienses, 12 y en parte, en Plutarco, Solón, 18 y Solón y Publícola 2.
} 


\section{REVISTA VIRTUAL VIA INVENIENDI ET IUDICANDI \\ "CAMINO DEL HALLAZGO Y DEL JUICIO"}

http://viei.usta.edu.co/ E-MAIL: revistainveniendi@usantotomas.edu.co

realidad que hay que controlar con la eunomía, el buen gobierno, evitando la hartura que conduce al abuso (hybris), imponiendo, en consecuencia, el orden que deviene del equilibrio entre las fuerzas de nobles y pueblo ${ }^{13}$. Pero en todo momento, él es el mediador, el árbitro ${ }^{14}$ que actúa con justicia pero que se erige como elemento extraño a los órdenes en conflicto para dar una solución al mismo $^{15}$. Él sabe que no va a contentar a nadie, que le va tener críticas por ambos bandos $^{16}$ pero, no obstante, está firmemente convencido de que sus medidas ${ }^{17}-y$ también su sacrificio ${ }^{18}$ - son el medio para llegar a una igualdad mayor entre nobles y pueblo ${ }^{19}$

\footnotetext{
13 "Al pueblo dí tanto honor cuanto le basta, sin nada quitarle de su dignidad, ni añadirle; los que tenían la fuerza y eran sobresalientes en riquezas, de éstos también cuidé para que nada vergonzoso sufrieran”, Aristóteles, Constitución de los atenienses, 12, 1 .

14 "Y me mantuve firme, levantando fuerte escudo ante ambos bandos, y no dejé ganar sin justicia a ninguno”, Aristóteles, Constitución de los Atenienses, 12,1.

15 "Yo entre éstos, como entre dos ejércitos, me establecí como límite". Aristóteles, Constitución de los Atenienses, 12,5

16 "Por ello, sacando vigor de todos los lados, como entre muchas perras un lobo, yo me revolvi’, Aristóteles, Constitución de los Atenienses, 12,4.

17 "[...] la negra Tierra, de la que yo antaño

los mojones arranqué en muchas partes hincados;

la que antes era esclava, es ahora libre.

A muchos, hacia Atenas, su patria fundada por los dioses,

traje que habían sido vendidos, unos sin justicia

otros justamente, a otros que por la apremiante

pobreza habian huído [...]

A los que aquí mismo en servidumbre vergonzosa

estaban, temblorosos ante el semblante de sus dueños,

los hice libres", Aristóteles, Constitución de los Atenienses, 12,4.

18 "Solón se opuso a unos y a otros, y pudiendo, con la ayuda de cualquiera de los dos bandos, establecerse como tirano, eligió hacerse odioso a ambos, salvando a la patria y legislando lo que fuera mejor", Aristóteles, Constitución de los Atenienses, 11,2.

19 "Escribí leyes igualmente para el pobre y el rico, acomodando justicia recta para cada uno”. Aristóteles, Constitución de los Atenienses, 12,4.
} 


\section{REVISTA VIRTUAL VIA INVENIENDI ET IUDICANDI}

"CAMINO DEL HALLAZGO Y DEL JUICIO"

http://viei.usta.edu.co/ E-MAIL: revistainveniendi@usantotomas.edu.co

Ciertamente Solón se nos presenta como un "aristócrata, porque consideraba que el pueblo tenía que estar sujeto por los mejores" (López Melero, 1989) con un "profundo convencimiento de la propia excelencia y la no menos profunda convicción de que las leyes deben ser impuestas por los mejores" (López Melero, 1989). Así lo recoge Plutarco en Solón: "preguntado después si había dado a los atenienses las mejores leyes, respondió: "De las que podian recibir, las mejores" 20 . Pero este aristócrata que cree en el equilibrio entre las clases como medio para conseguir la paz, tiene el mérito de considerar al pueblo como uno de los elementos básicos del nuevo orden y pese a lo que se puede deducir de algunas de sus palabras, la realidad de sus reformas abogan por un cambio de cierta instituciones políticas y jurídicas basado en un cierto espíritu democrático que se sustentaba, fundamentalmente, en dos principios básicos: 1) mayor representación y participación ciudadana y 3) sistema de límites.

En relación al primer aspecto, tenemos su reforma de las clases censitarias que respondían a un criterio patrimonial y cuya finalidad se ha apuntado que pudo ser militar más que política ${ }^{21}$. En cualquier caso, el criterio de la propiedad fondiaria $^{22}$ era el que determinaba la posición política de los ciudadanos, la

\footnotetext{
${ }^{20}$ Plutarco.Vidas Paralelas. Solón-Publícola. (A. R. Romanillos, Trad.) 1948, Buenos Aires, Austral..

${ }^{21}$ Vide en este sentido (Mossé, 2004, págs. 250-254).

${ }^{22}$ Acerca de la posibilidad de que se tuviera en cuenta para la tasación de la riqueza de cada ciudadano también la derivada de comercio e incipiente industria existen opiniones discrepantes en la doctrina. Íntimamente ligado a este problema está el de la atribución "al propio Solón de la fijación de la equivalencia entre la moneda y el medimno" (López Melero, 1989, pág. 16) esto es, la medida para áridos. A su vez Finley (1987, pág.140, n.2) señala la "atribución arbitraria de igualdad de valor entre las dos medidas" medimno y metretes, para líquidos, que presentaban distintas equivalencias, al igual que no se distinguía entre diferentes
} 


\section{REVISTA VIRTUAL VIA INVENIENDI ET IUDICANDI \\ "CAMINO DEL HALLAZGO Y DEL JUICIO" \\ http://viei.usta.edu.co/ E-MAIL: revistainveniendi@usantotomas.edu.co}

efectiva representación de todos los sectores de la población y, como consecuencia, su efectiva participación en la vida pública tanto en lo que se refiere al ejercicio de las magistraturas, cuanto a la toma de decisiones ${ }^{23}$. De ahí que el carácter timocrático de efectiva adscripción de los ciudadanos a las distintas clases, sea uno de los lastres que pesan a la hora de valorar el modelo soloniano -y los posteriores- como efectivamente democrático.

Dos medidas más sobresalen: en primer lugar, importantísima, la apelación al tribunal. Las propias fuentes antiguas -Aristóteles y Plutarco, fundamentalmente- dan cuenta sobrada del cambio que supuso esta reforma; el conceder la posibilidad de apelación a los ciudadanos ante determinadas decisiones de los magistrados ${ }^{24}$ supone el origen de unos de los principios básicos de todo ordenamiento democrático: la existencia de límites al poder. Plutarco lo señala de manera extraordinariamente gráfica: explicando la última de las clases censitarias señala que "todos los demás llamábanse proletarios o jornaleros, los cuales no eran admitidos a ninguna magistratura, y sólo en concurrir a las juntas y ser tomados para jueces participaban del gobierno. Esto, al principio, no era nada; pero luego vino a ser de gran consecuencia, porque las más de las controversias iban a parar a los jueces; por cuanto aun en aquellas cosas cuya determinación se

cultivos, lo que plantea a su vez la cuestión de si existía una valoración monetaria de la riqueza. Vidal-Naquet (1992, pág. 65), por su parte, entiende que en la solución ateniense no existe equilibrio entre propiedad territorial y producción artesanal. Evidentemente, estas cuestiones, interesantísimas sin duda, y que ponen una vez más en relación directa lo que sucede en Atenas y en Roma, exceden del propósito de este trabajo.

${ }^{23}$ Vide Aristóteles, Constitución de los atenienses, 7,3 y 4, y Plutarco, Solón, XVIII, para las clases censitarias y su participación en la vida pública.

${ }^{24}$ Plutarco, Solón, XVIII. 


\section{REVISTA VIRTUAL VIA INVENIENDI ET IUDICANDI}

"CAMINO DEL HALLAZGO Y DEL JUICIO"

http://viei.usta.edu.co/ E-MAIL: revistainveniendi@usantotomas.edu.co

había atribuído a los magistrados concedió apelación a los que quisiesen para ante los tribunales" (Solón, XVIII) ${ }^{25}$.

Pero si ésta fue la naturaleza de la medida stricto sensu, la consecuencia práctica fue más allá ya que la existencia de leyes poco claras permitían diferentes interpretaciones a los jueces que, de repente, se encontraron en su mano con una arma poderosísima ${ }^{26}$. Ahora bien, la idea de utilizar la interpretación de las leyes como arma de poder no parece que vaya a favor de la seguridad jurídica como concepto clave en todo sistema democrático ${ }^{27}$.

Esta consecuencia de la capacidad de influir en el gobierno a través de las decisiones tomadas por los miembros de los tribunales que pronto empieza a constatarse en la realidad práctica ateniense, contradice en cierto modo esa declaración de principios de Solón que partía del equilibrio en los órdenes y en su labor de árbitro. De su declaración primera en los fragmentos de sus versos:

"Al pueblo dí tanto honor cuanto le basta, sin nada quitarle de su dignidad, ni añadirle,28

o cuando dice:

\footnotetext{
25 “Con lo que dicen el pueblo consiguió más fuerza, la apelación al tribunal, pues al ser el pueblo dueño del voto, se hace dueño del gobierno", Aristóteles, Constitución, 9.

26 "Dícese además que, no habiendo escrito las leyes con bastante precisión, y teniendo éstas diferentes sentidos, con esto se acrecentó el poder de los tribunales, porque, no pudiendo dirimirse las diferencias por las leyes, sucedía que era necesario el ministerio de los jueces y había que acudir a ellos en todas las dudas, con lo que en algún modo tenían las leyes bajo su potestad", Plutarco, Solón, XVIII.

${ }^{27}$ Nada que ver, evidentemente, con la labor de interpretatio de los juristas romanos en el campo del derecho privado.

${ }^{28}$ Aristóteles, Constitución de los atenienses, 12, 1
} 


\section{REVISTA VIRTUAL VIA INVENIENDI ET IUDICANDI}

"CAMINO DEL HALLAZGO Y DEL JUICIO"

http://viei.usta.edu.co/ E-MAIL: revistainveniendi@usantotomas.edu.co

el pueblo así es como seguirá mejor a sus jefes, ni demasiado suelto ni en exceso apretado" ${ }^{29}$.

en las que parece poner al pueblo bajo una cierta custodia, el resultado práctico fue otro pudiendo pensarse que en Solón pesó más el ánimo de favorecer al pueblo dándole un mayor poder que a los demás órdenes ${ }^{30}$, impresión que vemos reflejada en Plutarco cuando dice: "Advirtiendo que todavía convenía dar más auxilio a la flaqueza de la plebe, concedió indistintamente a todos el poder presentar querella en nombre del que hubiese sido agraviado"31. Esta medida se nos presenta como una especie de acción popular en la que cualquiera puede intentar el ejercicio de las acciones correspondientes a los derecho ajenos en un intento, probablemente, de que los ciudadanos se sintieran unidos "como miembros de un mismo cuerpo" (Plutarco, Solón, XVIII), buscando, quizá, la identidad de clase o buscando, quizá, la identidad de ciudadano ${ }^{32}$. Esta sería la segunda medida en cuanto a la participación ciudadana: presentar a los ciudadanos la posibilidad de ser protagonistas, agentes del destino de la ciudad.

\footnotetext{
${ }^{29}$ Aristóteles, Constitución, 12, 2.

${ }^{30}$ Incluso en las fuentes antiguas se recoge la información de que en su tiempo se pensó que la poca claridad de las leyes había sido un medio utilizado conscientemente por Solón para provocar esa posición preeminente del pueblo; vide Aristóteles, Constitución, 9 y Plutarco, Solón, XVIII. Acerca de que Solón fue más lejos de lo que dicen sus versos y que sí dio más honor al pueblo se pronuncia Rodríguez Adrados (1997, pág. 62).

${ }^{31}$ Plutarco, Solón, XVIII.

${ }^{32}$ Probablemente en esta línea, la medida tomada por Solón - de la que se extraña Plutarco- sobre la prescripción de la nota de infamia, atimía, que conllevaba la exclusión de la comunidad ciudadana y privación de los derechos para aquél que "en una sedición no hubiera sido de ninguno de los dos partidos". Se intentaba evitar que nadie "fuera indiferente o insensible en las cosas públicas" ocupándose sólo de las suyas, Solón, XX. También en Aristóteles, Constitución., 8,5.
} 


\section{REVISTA VIRTUAL VIA INVENIENDI ET IUDICANDI}

"CAMINO DEL HALLAZGO Y DEL JUICIO"

http://viei.usta.edu.co/ E-MAIL: revistainveniendi@usantotomas.edu.co

Y todo lo dicho bajo la gran medida soloniana: la prohibición de los préstamos poniendo como garantía la propia persona que, unida a las cancelación de las deudas -seisákhtheia- y a la reforma monetaria ${ }^{33}$, puso las bases del plan igualitario basado en su idea de justicia de Solón.

Mayor participación, mayor representación, y establecimiento de límites al ejercicio del poder de los magistrados. Si tenemos en cuenta que estos mismos principios deben estar en la base de cualquier democracia, la conclusión será que las medidas de Solón incorporan elementos o principios democráticos antes no conocidos. ¿Se corresponden estas medidas con la imagen de la que sería la primera personalidad con un perfil filosófico-político democrático que encontramos en Atenas? No lo podemos afirmar tajantemente; probablemente fue el aristócrata que fue: "por nacimiento y reputación, uno de los primeros, y por la hacienda y por sus ocupaciones, uno de los del medio" (Aristóteles, Constitución., 5,3) un hombre que se puso en el lugar del pueblo empobrecido y que su fundamental medida fue la de mejorar la situación económica de los ciudadanos, "un aristócrata que se hubiera solidarizado con los pobres" (Finley M. I., La Grecia primitiva: edad de bronce y era arcaica, 1987, pág. 139). En los fragmentos de sus versos las únicas medidas por él mencionadas son las económicas; fueron estas medidas de las que más se enorgullecía porque fueron el camino hacia la igualdad al afectar

\footnotetext{
${ }^{33}$ Aristóteles, Constitución., 6, 9 y 10; Plutarco, Solón, XV, que recoge la información de que no fue la extinción de los créditos sino la moderación de los intereses lo que alivió a los más pobres. Sobre la importancia de la acuñación de moneda y las políticas monetarias en la política en general en el mundo antiguo vide (Torrent Ruiz, 2007)
} 


\section{REVISTA VIRTUAL VIA INVENIENDI ET IUDICANDI}

"CAMINO DEL HALLAZGO Y DEL JUICIO"

http://viei.usta.edu.co/ E-MAIL: revistainveniendi@usantotomas.edu.co

también al plano político reintegrando como ciudadanos a aquéllas personas que, por deudas, se encontraban en situaciones de esclavitud o cuasiesclavitud ${ }^{34}$. Como señala Gil, la reforma de Solón pretendió resolver las tensiones sociales que se habían generado por el paso de una economía natural a una monetaria y que había determinado que "la separación entre libres y esclavos ya no se establecía entre connacionales y extranjeros [...] sino también entre acreedores y deudores insolventes" (1989, pág. 45).

Esta idea me parece que es la transciende a las reformas de Solón: con la reintegración de esos ciudadanos se abre una concepción del pueblo como un elemento de la constitución ateniense, con un sentido identitario que cohesiona internamente a las personas que lo $\operatorname{componen}^{35}$ y que, a su vez, lo distingue de los no-ciudadanos ${ }^{36}$.

Igualdad y equilibrio, en definitiva, son los ejes sobre el que gira su eunomía, su buen gobierno ${ }^{37}$ pero sobre la base de un pueblo, un dêmos que se siente y ejerce como tal, "un pueblo todo, opuesto a "los pobres" (Rodríguez

\footnotetext{
34 "Y a muchos a Atenas, a su patria fundada por los dioses, los traje de nuevo cuando habían sido vendidos, (...) y a los que por la fuerza de la necesidad se habían exiliado (...) y a los que, aquí mismo una esclavitud indigna soportaban (...) los hice libres", Aristóteles, Constitución., 12,4 frag. de los versos. Sobre la utilización del término esclavo (Finley M. I., 1977, pág. 95 y ss) en la sociedad arcaica (Finley M. I., 1987, pág. 118 y ss).

${ }^{35}$ El pueblo, dêmos, con el sentido ambivalente de pueblo llano o conjunto de todo el pueblo en que lo encontramos utilizado en los primeros momentos de la democracia ateniense (Finley M. I., 1987, pág. 120)

${ }^{36}$ Crifò ha expresado la idea de que ciuis es un concepto recíproco en tanto en cuanto una persona es ciuis respecto de otro al que, a su vez, el primero le reconoce esa condición (Crifò, 2000, pág. 26)

37 "[...] que la igualdad no engendra discordia y acomoda a ricos y pobres" Plutarco, Solón, XIV.
} 


\section{REVISTA VIRTUAL VIA INVENIENDI ET IUDICANDI}

"CAMINO DEL HALLAZGO Y DEL JUICIO"

http://viei.usta.edu.co/ E-MAIL: revistainveniendi@usantotomas.edu.co

Adrados, 1997, pág. 62). Por eso, quizá también, no cayó en la tiranía lo que habría resultado casi lo más fácil ${ }^{38}$. Después vendrían las demás medidas con sus soplos de aires democráticos.

El segundo gran paso hacia la democracia en Atenas lo dio Clístenes (508 a.C.). Sus reformas se basan en otro gran principio: la isonomía o igualdad legal. Los antiguos demos fueron reformados convirtiéndolos en unidades administrativas que suponían el primer peldaño dentro del esquema constitucional ciudadano; como señala López Melero (1989, pág. 48) los demos existían antes de Clístenes y se configuraban como unidades de población rural de distinta extensión. Con Clístenes se estructuran como la demarcación de pertenencia ciudadana más cercana al individuo ${ }^{39}$ de la que saldrían los posibles miembros de la Boulè ${ }^{40}$.

A su vez creó nuevas tribus ${ }^{41}$ territoriales (10) que, parece, disminuyeron el poder que hasta entonces tenían las grandes familias nobles. Está también generalmente admitido que Clístenes creó el Consejo de los Quinientos,-(Boulé)-, “democrático y predeliberativo" (Sancho Rocher, 2005, pág. 180), instancia

\footnotetext{
38 Vide ampliamente Aristóteles, Constitución., 6, 3 y 4; 11, 2 in fine y los fragmentos de sus versos; Plutarco, Solón, XIV.

${ }^{39}$ Ejercían funciones de registro civil que les ratificaba en su condición de ciudadanos pasando, incluso, la mención del demos al que pertenecía un ciudadano a ser parte de su nombre o identificación (López Melero, 1989).

${ }^{40}$ Los demos votan a una serie de ciudadanos de entre los cuales saldrán elegidos, por sorteo, 50 por cada tribu (Rodríguez Adrados, 1997).

${ }^{41}$ Que englobaban a los demos.
} 


\section{REVISTA VIRTUAL VIA INVENIENDI ET IUDICANDI}

"CAMINO DEL HALLAZGO Y DEL JUICIO"

http://viei.usta.edu.co/ E-MAIL: revistainveniendi@usantotomas.edu.co

intermedia de la Asamblea o Ekklesia que nacía con la función de la proboúlensis que consistía en un filtro de los asuntos que se tenían que discutir en la asamblea ciudadana. A partir de ahora la Ekklesia sólo podría tratar temas propuestos por el Consejo de los Quinientos.

La composición de la Boulé o Consejo de los Quinientos está formado por un número de ciudadanos, 50 por cada tribu, designados por sorteo. Los ciudadanos que integraban el Consejo son también ciudadanos que integraban la Asamblea o Ekklesia, por tanto, no interfiere un órgano extraño a la Asamblea de ciudadanos en esta labor previa de tratamiento de asuntos lo que se podría haber visto como un intento claro de limitación del poder ciudadano (López Melero, 1989).

Como se puede deducir, el objeto de las medidas fueron las instituciones jurídico-políticas atenienses ${ }^{42}$ y más concretamente las relacionadas con la participación ciudadana. Como señala Plácido Suárez, "las condiciones de la participación ciudadana no sólo dejan de ser puramente gentilicias, sino que se opera una ampliación, marcada por la integración de los que Aristóteles llama "esclavos metecos", los que antes de la nueva integración ciudadana quedaban en posición marginal, susceptible de definirse como metecos o de caer en la esclavitud" (2007, pág. 140).

\footnotetext{
${ }^{42}$ Queda también reflejada en las fuentes una reforma dirigida al aumento del número de ciudadanos y una partición de Atenas en nuevos demos.
} 


\section{REVISTA VIRTUAL VIA INVENIENDI ET IUDICANDI}

"CAMINO DEL HALLAZGO Y DEL JUICIO"

http://viei.usta.edu.co/ E-MAIL: revistainveniendi@usantotomas.edu.co

¿Podemos pensar que, unido a la reordenación ciudadana ${ }^{43}$ en demos, tribus, Consejo y Ekklesia, éste sea el momento en el que nace, siquiera tímidamente, la idea de la representación?.

Que 500 ciudadanos tengan esta misión de preparar los asuntos que debían ser votados por el resto de sus conciudadanos es una idea de representación extraña a nuestra idea actual de la misma; lo es, desde luego, el sistema de selección de los Quinientos ciudadanos, que se hace por sorteo ${ }^{44}$ y también lo es, debido precisamente al modo de selección de los mismos, que esos 500 ciudadanos son, lo que podríamos llamar, ciudadanos del común y no como sucede la mayoría de los sistemas actuales en la que los aparatos de los partidos políticos ejercen un cuasi monopolio de la representación ${ }^{45}$. Por último, resulta también extraño porque en nuestras democracias actuales la representación se basa en la delegación de la soberanía del pueblo al representante, mientras que la "selección de los consejeros atenienses [...] no es una prolongación de la soberanía de sus conciudadanos, sino el ejercicio directo por parte del

\footnotetext{
${ }^{43}$ La reordenación jurídica-administrativa es más compleja con órganos que aquí no mencionamos.

${ }^{44}$ De entre los votados en los demos.

45 Excepción hecha de algunas particularidades que a nivel electoral y representativo puedan tener los distintos países como es el caso del Concejo Abierto en España que, debido a unas determinadas circunstancias o históricas o demo-geográficas reconoce participación de todos los electores en un régimen de tipo asambleario. En referencia a ejemplos relacionados con la democracia participativa fuera de España y los problemas a los que también este tipo de democracia tiene que hacer frente, vide ampliamente (Maíz, 2006, págs. 28-30).
} 


\section{REVISTA VIRTUAL VIA INVENIENDI ET IUDICANDI}

"CAMINO DEL HALLAZGO Y DEL JUICIO"

http://viei.usta.edu.co/E-MAIL: revistainveniendi@usantotomas.edu.co

seleccionado de un derecho asociado a su dignidad de ciudadano" (Sancho Rocher, 2005, pág. 183) ${ }^{46}$

Esta utilización del sorteo es muy frecuente en Atenas: parte, en definitiva, de una concepción tremendamente igualitaria (Rodríguez Adrados, 1997) y es que cualquier ciudadano está capacitado para ejercer funciones políticas; la duración anual del mandato y la prohibición de que fueran reelegidos abundan en esta idea de la igualdad participativa, puesto que se está fomentando la renovación permanente: todos los ciudadanos tendrían en el Consejo a cincuenta miembros de su misma tribu, al igual de que todos podrían ser en su momento uno de esos cincuenta.

No obstante, la medida tenía también su finalidad; al igual que, como relata Aristóteles, la creación de las tribus fue hecha "con la intención de mezclarlos (a los ciudadanos), para que participase mayor número en el gobierno" (Const., 21,2), con el Consejo de los Quinientos se tenía un mayor control sobre los asuntos a tratar que si directamente éstos iban a la Asamblea, sobre todo si tenemos en cuenta que antes de la creación del Consejo de los Quinientos en la Asamblea o Ekklesia se podía tratar cualquier asunto y decidir sobre él; el conocimiento previo de las propuestas a tratar determinaría también en la práctica

\footnotetext{
${ }^{46}$ Sin embargo, el resultado de las reformas de Clístenes nos presentan un sistema de gobierno muy parecido a cualquier sistema democrático parlamentario actual, vide ampliamente (Gil, 1996).
} 


\section{REVISTA VIRTUAL VIA INVENIENIDI ET IUDICANDI \\ "CAMINO DEL HALLAZGO Y DEL JUICIO" \\ http://viei.usta.edu.co/E-MAIL: revistainveniendi@usantotomas.edu.co}

que la presencia en la Asamblea estuviera garantizada tanto de partidarios como de posibles contrarios a la misma (López Melero, 1989).

En cualquier caso, parece que el conjunto de medidas adoptadas por Clístenes tenían como objetivo fundamental ampliar el número de ciudadanos que de hecho, y quizá también de derecho ${ }^{47}$, participaban en la vida pública. La isonomía de Clístenes, la igualdad legal, que Heródoto que pone en boca del príncipe Otanes encargado de la defensa del "gobierno del pueblo" (Historia, III, 80-8248: "En cambio, el gobierno del pueblo tiene, de entrada, el nombre más hermoso: "isonomía" -igualdad legal-; y explica en qué consiste ésta: "las magistraturas se desempeñan por sorteo, cada uno rinde cuentas de su cargo y todas las deliberaciones se someten a la comunidad'. De nuevo se reafirma la idea de "sorteo" como el modo más democrático, en cuanto igualitario, a la hora de elegir a las personas encargadas de la gestión de asuntos públicos, y que cualifica la participación, pero también se introduce la idea de la responsabilidad en el ejercicio del cargo y se remarca la de deliberación del pueblo.

\footnotetext{
${ }^{47}$ Que participasen de la politeia -conjunto de las instituciones políticas- un número mayor. La traducción de la expresión es dudosa no sólo porque podría ser considerada como una ampliación del derecho de ciudadanía (López Melero, 1989), sino también porque según se elija en la traducción una expresión como "conjunto de las instituciones políticas" frente a "ciudadanía" podría tener diferentes connotaciones. Resalta este doble significado Sartori considerando revelador de la esencia de la democracia ateniense "que politeia significara a la vez ciudadanía y estructura" -constitución- recogiendo las palabras de Tucídides ándres gar polis "(son los hombres los que son la polis)" (1988, pág. 343).

${ }^{48}$ Vide al respecto, (Sousa, 2005)
} 


\section{REVISTA VIRTUAL VIA INVENIENDI ET IUDICANDI \\ "CAMINO DEL HALLAZGO Y DEL JUICIO" \\ http://viei.usta.edu.co/ E-MAIL: revistainveniendi@usantotomas.edu.co}

Como ha señalado Rodríguez Adrados todavía no se utiliza la expresión democracia para referirse a este sistema de gobierno (Rodríguez Adrados, 1997) pero es que probablemente todavía estemos en ese punto en el que lo importante sea mantener el equilibrio entre los órdenes que se traducía, en definitiva, en el mantenimiento de la correlación de fuerzas existentes entre los distintos órganos de gobierno o de poder atenienses ${ }^{49}$; en este sentido, todo lo que fuera incrementar la participación tanto directa como indirecta del pueblo en los distintos órganos constitucionales o en las decisiones por ellos tomadas suponía un granito más en el platillo del pueblo frente al de los nobles en esa balanza ideal que supuso primero Solón y luego Clístenes. Éste es el paso fundamental hacia un sistema político en el que el pueblo tiene un mayor poder decisorio en la politeia que el resto de los órganos constitucionales ${ }^{50}$.

A partir de aquí, Efilates primero (462 a.C.) y luego Pericles consolidan la democracia. El mismo acceso al poder de Efialtes se logra a través de los órganos constitucionales en los que el pueblo participaba y las distintas reformas constitucionales que se llevaron a cabo lo fueron con la aprobación del Consejo y de la Ekklesia y a través de la utilización de los tribunales que, como sabemos, ya

\footnotetext{
${ }^{49}$ Interesantísima y muy gráfica la cita de Rodríguez Adrados acerca de la utilización del término isonomía por Alcmeón de Crotona hablando sobre medicina: la salud es una mezcla moderada de potencias opuestas (Rodríguez Adrados, 1997, pág. 80).

${ }^{50}$ El liderazgo de Clístenes no dependía de una autoridad constitucional, sino de su habilidad para persuadir al pueblo ateniense de que se comportara y actuara conforme a los propósitos por él defendidos; en este sentido el pueblo es el que tiene un papel más decisivo que el propio Clístenes -siendo importante- en la historia de la democracia ateniense (Ober, 2004, pág. 264). Hay que tener en cuenta que este autor rechaza la idea de que en general la historia, y en particular la democracia ateniense, se construya a base de concesiones de una élite dirigente a un pueblo pasivo.
} 


\section{REVISTA VIRTUAL VIA INVENIENDI ET IUDICANDI}

"CAMINO DEL HALLAZGO Y DEL JUICIO"

http://viei.usta.edu.co/ E-MAIL: revistainveniendi@usantotomas.edu.co

desde las reformas de Solón estaban compuestos por ciudadanos (Rodríguez Adrados, 1997) y que a partir de las reformas de Efialtes cobran verdaderamente un mayor poder ${ }^{51}$.

La desaparición del Areópago desde el punto de vista del poder político, al privarle Efialtes de sus poderes en relación al control de las leyes -"guardián de las leyes- y, en general, del orden constitucional, traspasándoselo al consejo de los Quinientos y a los tribunales -esto es, al pueblo- supuso verdaderamente hacer al dêmos protagonista de la politeia, de la constitución (Mossé, 2004, pág. 256) lo que nos presenta un esquema constitucional en Atenas de unos órganos participados plenamente por el pueblo en los que el equilibrio entre los órdenes se ha roto.

Es en esta época, probablemente, cuando surge, como tal, el término demokratía; también, como señala Rodríguez Adrados (1997), aristokratía y oligarkhía, todos ellos como términos contrapuestos entre sí, indicativos de diferentes formas de gobierno partiendo de la idea de que, aunque en toda sociedad siempre habrá pueblo, aristócratas y oligarcas, el gobierno de una sociedad se definirá por cuál de los tres elementos es el que tiene el poder en cada momento y si no el poder, sí al menos, la prevalencia. Términos que, en

\footnotetext{
${ }^{51}$ La medida de la participación del pueblo en los tribunales tomada por Solón no habría tenido ninguna eficacia efectiva mientras el Areópago hubiera mantenido el control de las leyes (Mossé, 2004, pág. 256). Y hemos visto, por el contrario, la importancia concedida por Aristóteles a este hecho.
} 


\section{REVISTA VIRTUAL VIA INVENIENDI ET IUDICANDI}

"CAMINO DEL HALLAZGO Y DEL JUICIO"

http://viei.usta.edu.co/ E-MAIL: revistainveniendi@usantotomas.edu.co

consecuencia, y a partir de entonces, se consideran excluyentes entre sí en cuanto designan distintas formas de gobierno, pero que en función de las distintas perspectivas en que sean consideradas las realidades que designan, pueden ser intercambiables.

Los propios historiadores antiguos se dieron cuenta del fino límite que en ocasiones distinguía una y otra forma de gobierno y cómo dependiendo de quién fuera el sujeto que analizara la situación calificaría la realidad de una manera u otra: Plácido nos recuerda cómo Tucídides usa la palabra tiranía para definir lo que hace Atenas y que refleja lo contradictorio del dêmos ateniense, tanto a nivel interno, cuando Pericles estuvo al frente de la ciudad que, de nombre, era una democracia pero que, de hecho, era el poder del primer hombre ${ }^{52}$; y también en el exterior donde ejerce la tiranía del imperio con el resto de las ciudades griegas aunque sea para impedir que éstas caigan en la tiranía o en la oligarquía (Plácido Suarez, 1989). Independientemente de la opinión que se tenga sobre las intenciones políticas de los protagonistas, lo cierto es Efialtes, primero y Pericles después, cierran un ciclo evolutivo.

Ya no se echaron más granitos de arena al platillo. Desaparecido el sistema basado en el equilibrio entre los órdenes nos encontramos con que uno de ellos, el dêmos, es el que tiene el poder y difícilmente perderá lo ya ganado.

\footnotetext{
${ }^{52}$ Vide Rodriguez Adrados en contra de esta visión que Tucídides tiene de Pericles (1997, págs. 142-143).
} 


\section{REVISTA VIRTUAL VIA INVENIENDI ET IUDICANDI}

"CAMINO DEL HALLAZGO Y DEL JUICIO"

http://viei.usta.edu.co/E-MAIL: revistainveniendi@usantotomas.edu.co

\subsection{Roma.}

Aunque la República Romana comienza en el año 509 a.C. es sólo a partir del 367 a.C. cuando encontramos unas instituciones suficientemente consolidadas como para hablar de un sistema basado en principios democráticos; sobre todo porque es a partir de ese momento cuando el pueblo, el populus romanus, ha cerrado las viejas distinciones entre patricios y plebeyos y encontramos una nueva sociedad que los ha integrado a todos ${ }^{53}$. Relativamente, podríamos decir aquí también, como lo hemos dicho en el caso de Atenas, porque a las viejas clases sustituye una nueva, la nobilitas que integrada por patricios y plebeyos refleja la clase social detentadora del poder. Las diferencias, ahora, están más marcadas por el predominio de la riqueza, inmobiliaria y mobiliaria, que por otras razones.

Si pensamos en una especie de "Historia de la Democracia Romana" la sucesión de imágenes que pasan ante nosotros ${ }^{54}$ probablemente sería la caída de la monarquía (509 a.C.) -libertas-, la primera secesión plebeya (494 a.C) con el nacimiento de los tribunos como magistrados plebeyos -límite al poder de la clase dominante-, Ley de las XII Tablas -seguridad jurídica-; las leges Liciniae Sextiaela igualdad- o la lex Poetelia Papiria de nexis (326 a.C.) -la nueva libertad ${ }^{55}$-, por

\footnotetext{
${ }^{53}$ Sartori ha planteado los problemas que se suscitan, también en la actualidad, al entender el pueblo como todos (Sartori, 2007, pág. 28 y ss.)

${ }_{55}^{54}$ Es un mero ejemplo sin ningún afán de exhaustividad, seguro que incompleta y probablemente mejorable.

${ }^{55}$ Este ley mitigó la antigua ferocidad de la ejecución personal establecida para los deudores insolventes estableciendo que pecuniae creditae bona debitoris non corpus obnoxium esse, (Livio VIII, 28, 9), esto es, abolió la prisión por deudas al establecer que los bienes del deudor y no su propia persona fueran los que respondieran en caso de impago (Rotondi, 1990). Como señala Livio, "Aquél año se le proporcionó a la plebe
} 


\section{REVISTA VIRTUAL VIA INVENIENDI ET IUDICANDI \\ "CAMINO DEL HALLAZGO Y DEL JUICIO" \\ http://viei.usta.edu.co/ E-MAIL: revistainveniendi@usantotomas.edu.co}

nombrar sólo algunos de los primeros jalones (podríamos seguir con el plebiscito Ovinio (hacia el 318 a.C) ${ }^{56}$, la reforma de las tribus (312 a.C.), la publicación del calendario judicial y de las fórmulas de las acciones por Cneo Flavio (304 a.C), la lex Ogulnia (300 a.C.) que acabó con el último reducto monopolístico de los patricios: los colegios sacerdotales, o mucho más reciente, la introducción del voto secreto, en el 139 a.C. derivado de las grandes luchas sostenidas por movimientos democráticos (Salerno, 1999, pág. 127 y 128). Todas ellas dan muestra clara del largo camino en la conquista de mayores libertades ${ }^{57}$ para el común de los ciudadanos con la consiguiente sustracción de poderes a las clases dominantes; sin embargo, y aunque las he "renombrado" con una o unas palabras "clave" -libertas, límite al poder, igualdad, seguridad jurídica, etc- salvo la primera, libertas, que incorpora uno de los elemento nucleares de la república, ninguna define per se lo que era el régimen republicano frente a lo que hemos visto que sucedía en Atenas en las que las palabras eunomía, isonomía, demokratía van unidas a estos jalones de los que hablamos. No hay palabra más que re publica y la imagen que en la mente de cada uno se forma cuando ésta se pronuncia: libertas. El pueblo romano -aunque fuera a través de una revuelta de los propios nobles frente a los reyes- crea en el 509 a.C. un nuevo régimen constitucional, la república que se basa en la libertas recién ganada y, a partir de ahí, todo el

romana, en cierto modo, un nuevo estreno de la libertad, porque dejó de haber esclavitud por deudas" (VIII, $28,1)$.

${ }^{56}$ La cronología habitual lo data unos años más tarde; yo propuse en su día una datación unos años antes del 318 a.C. Vide ampliamente (Valmaña Ochaíta, 1995, págs. 91-102).

57 Todas pueden ser consideradas libertas; vide en este sentido, (Sánchez de la Torre, Procesos de la participación política en la República romana: reflexiones entre Tito Livio y Maquiavelo, 1996). 


\section{REVISTA VIRTUAL VIA INVENIENDI ET IUDICANDI \\ "CAMINO DEL HALLAZGO Y DEL JUICIO" \\ http://viei.usta.edu.co/ E-MAIL: revistainveniendi@usantotomas.edu.co}

régimen republicano gira en torno al mantenimiento y engrandecimiento de esa libertas.

Por ello, desde mi punto de vista lo más destacado de la república romana son las relaciones entre los distintos órganos de poder que consiguen un sistema de equilibrios que permiten la no pérdida de la libertas ${ }^{58}$. Lo primero que resalta Livio (II, 1,1 y 1,7) de la instauración de la república es que el poder se había limitado temporalmente; realmente, salvo el rex, los demás órganos se mantenían: sólo había que limitar a los nuevos sustitutos del poder regio. En este sentido, quizá Roma no llegó nunca a un predominio del pueblo respecto de los restantes órganos de poder como pudo haber en Atenas, al menos en ciertos momentos de Atenas. De hecho, para muchos autores la prevalencia del poder estaba en la República en manos del Senado y no del pueblo. Lo que sí es cierto es que en Roma el equilibrio entre poderes fue más permanente; entre los poderes señalados se establecen unos lazos y controles poderosos que a veces impiden identificar bien cuál fue el sistema político de la república romana, esto es, el sistema político coincidente con alguno de los existentes en su época y que Polibio $(6,5)$ consagró como constitución mixta: si nos fijamos en el poder de los magistrados, parece una monarquía, si en el poder del Senado, una aristocracia;

\footnotetext{
58 Y la república acaba, además de por otros muchos motivos, cuando se rompe el equilibrio, fundamentalmente, por el declive de las asambleas populares que venían lastrando el problema del personalismo de ciertos candidatos que fácilmente arrastraban un gran número de votos. Se ha dicho también, que las instituciones republicanas fueron incapaces, por insuficientes, de hacer frente a los nuevos problemas que planteaba no ya la ciuitas, sino el imperio. Branca (1960, pág. 222) sostiene que la república cae porque en Roma no existía una democracia de verdad, una democracia sustancial: si la hubiera habido en el momento en que hubiera aparecido la crisis, las facciones no habrían combatido a mano armada.
} 


\section{REVISTA VIRTUAL VIA INVENIENDI ET IUDICANDI}

"CAMINO DEL HALLAZGO Y DEL JUICIO"

http://viei.usta.edu.co/ E-MAIL: revistainveniendi@usantotomas.edu.co

si nos fijamos en el poder de las asambleas populares, una democracia, planteamiento que sigue Cicerón frente al sistema dual que propone Salustio basado en la auctoritas del Senado frente a la vis de la plebe (Torrent, 2002).

Partiendo de esta premisa me interesa remarcar unas ideas fundamentales para entender la República Romana y los principios democráticos que subyacen en ella:

¿Existe en Roma la idea de la participación y participación directa, como en Atenas?. Todo ciudadano está llamado a participar en la asamblea y en la asamblea se legisla, se elige a los magistrados y se toman decisiones en materia jurisdiccional cuando afectan a sentencias sobre pena capital a un ciudadano romano, además de otras. Ahora bien, la estructura y composición de la asamblea centuriada determinaba que, en la práctica, sólo ciertos ciudadanos, los que pertenecía a las clases censitarias más altas, ejercitaran su derecho a voto. Y la pertenencia a las clases censitarias venía marcada, como en Atenas, por la riqueza que se poseyera; dicho de otra manera, estamos ante un sistema timocrático. Pero también es cierto, como ya hemos señalado, que en Roma existieron otras asambleas en las que los criterios de adscripción y efectiva participación ciudadana fueron mucho más permeables a los influjos democráticos. Y la verdad es que los ciudadanos participaban en la actividad legislativa y votaban en los comicios, -sobre todo a partir de las reformas de las 


\section{REVISTA VIRTUAL VIA INVENIENDI ET IUDICANDI}

"CAMINO DEL HALLAZGO Y DEL JUICIO"

http://viei.usta.edu.co/ E-MAIL: revistainveniendi@usantotomas.edu.co

tribus en las que se incluye, la tasación de la riqueza mobiliaria, hasta entonces excluída, y la posibilidad de elección por parte de cada ciudadano de la tribu de su preferencia para ser inscrito en ella ${ }^{59}$ - de manera directa al gobierno del Estado (Branca, 1960).

Pero que unos órganos constitucionales controlen o limiten a otros supone, a su vez, que son también controlados o limitados: decisiones tomadas por las asambleas populares tenían que pasar por un filtro externo: el Senado. Éste, primero, aplicando una especie de control de legalidad a la decisión tomada por la asamblea y con el paso del tiempo, de forma preventiva, de la propuesta que se llevaba a la asamblea para su votación, cuestionaba en gran medida la capacidad deliberante de la asamblea. Además, los propios magistrados ejercen un fuerte control sobre los comicios que presiden o las propuestas que hacen llegar a los ciudadanos. También existen límites a la voluntad del populus no sólo en cuanto al sistema, sino también competenciales, como los que señala Catalano (Catalano, 1962, pág. 324) en relación al fundamento del poder y al poder mismo como el caso de la obnuntiatio ${ }^{60}$ y a la imposibilidad del populus de nombrar sacerdotes.

Por su parte, el poder magistratual se ve limitado por un control externo que fue la figura del tribuno de la plebe; la figura que habiendo nacido de las luchas

\footnotetext{
${ }^{59}$ Vide ampliamente (Valmaña Ochaíta, 1995) y (Valmaña Ochaíta, 1998).

${ }^{60}$ Suponía la afirmación por parte de los sacerdotes de que los dioses eran desfavorables, una vez averiguada su voluntad lo que supuso una actuación con la que muchas veces la oligarquía desechaba las aspiraciones populares, vide s.v. obnuntiatio (Torrent Ruiz, 2005).
} 


\section{REVISTA VIRTUAL VIA INVENIENDI ET IUDICANDI}

"CAMINO DEL HALLAZGO Y DEL JUICIO"

http://viei.usta.edu.co/ E-MAIL: revistainveniendi@usantotomas.edu.co

entre patricios y plebeyos se constituye como el defensor de los intereses de la plebe y pronto, como el máximo custodio de las libertades personales contra el súperpoder de los órganos del Estado" (Branca, 1960, pág. 204), es decir, superando su concepción de magistrado de la plebe, la auxilii latio adversus consules, poder fundamental de veto de las decisiones consulares, le convierte en el garante de los derechos de los ciudadanos en general. El populus también ejerció un importante límite sobre los magistrados a través de la provocatio ad populum y reglas como la capite ciuis aparecieron desde antiguo para defender a los ciudadanos de las decisiones tomadas en virtud del imperium de los magistrados ${ }^{61}$ lo que pone de manifiesto el hecho de que el pueblo es, desde muy temprano ${ }^{62}$, consciente de su identidad como órgano o elemento diferente del resto y, lo que es más importante, que el resto de órganos son conscientes de ello hasta el punto de aceptar una norma sobre tan importante límite.

No obstante las carencias o deficiencias del sistema republicano romano lo cierto es que se observa una constante evolución hacia cotas más elevadas de participación y deliberación del populus: El concurso o participación del pueblo se hace necesario ya desde la lex curiata de imperio y de la lex de bello indicendo. La idea de deliberación sólo llegará, como hemos dicho, con la perfección de la República y vendrá asociada a una suficiente publicidad de las propuestas presentadas a los comicios; buena muestra de ello es la existencia de contiones,

\footnotetext{
${ }^{61} \mathrm{O}$ de su iurisdictio, según sigamos las diferentes teorías al respecto.

${ }^{62}$ La regla de capite ciuis aparece recogida en la Ley de las XII Tablas.
} 


\section{REVISTA VIRTUAL VIA INVENIENDI ET IUDICANDI}

"CAMINO DEL HALLAZGO Y DEL JUICIO"

http://viei.usta.edu.co/ E-MAIL: revistainveniendi@usantotomas.edu.co

reuniones preparatorias del comicio popular en la que se pronunciaban discursos a favor o en contra de dichas propuestas. En este sentido, siendo la participación del pueblo romano una participación directa y no a través de representantes en la función legislativa, nos encontramos con un grado mayor de intervención y conocimiento de la norma a aprobar que en muchos sistemas actuales.

Ahora bien, la pregunta que debemos hacernos es si realmente era una participación directa. En Roma la unidad votante era la curia, la tribu o la centuria y si su voluntad se formaba con la suma de los votos individuales, la voluntad de la asamblea se formaba con la suma de las voluntades de cada tribu o centuria. Como señala Salerno (Salerno, 1999, pág. 77) se realizaba un sistema de toma de decisión en el cual la expresión del voto no tenía igual valor para todos los ciudadanos; pero, además, como no creció el número de centurias -establecida en 193- ni la de tribus -35- al compás del incremento ciudadano, los nuevos ciues entraron en las existentes lo que ha llevado a entender que la voluntad de la ciuitas tal como viene a formarse en las asambleas populares no se manifiesta como el resultado de la suma de voluntades de individuos iguales en términos de derecho (Salerno, 1999). Por si fuera poco, de facto, sólo participaban los ciudadanos que se encontraban en Roma, dentro de sus muros, ya que aquéllos que vivían en la Italia central, meridional, o septentrional no tenían posibilidades de participar en el día a día de la política romana (Branca, 1960, pág. 208) 


\section{REVISTA VIRTUAL VIA INVENIENDI ET IUDICANDI \\ "CAMINO DEL HALLAZGO Y DEL JUICIO"}

http://viei.usta.edu.co/ E-MAIL: revistainveniendi@usantotomas.edu.co

Objeciones serias, por tanto, a la idea de participación directa y efectiva.

\subsection{Paralelismos.}

Ya hemos señalado que las instituciones jurídico-políticas en Roma reproducen básicamente las existentes en el mundo heleno. Sin embargo, en el desarrollo democrático de las instituciones y creo que también en el mismo planteamiento del esquema democrático-constitucional encontramos diferencias entre Roma y Atenas. En relación al primer aspecto, la participación en Atenas fue una realidad democrática mayor que en Roma; como ha puesto de manifiesto Sancho Rocher (2005, págs. 181-183), la huída de la profesionalización en el ejercicio del poder, y la participación directa de los ciudadanos atenienses en las distintas instituciones jurídico-políticas les exigía una disponibilidad enorme para el servicio a la polis, por lo que se necesitó implicar a toda la población. Atenas consiguió un sistema en el que la democracia generaba más democracia.

La participación en Roma se concreta a través de la existencia de varias asambleas populares con distintas funciones y con criterios de pertenencia 0 adscripción diferentes ${ }^{63}$, pero sobre todo la existencia de una asamblea que no siendo de todo el populus sino sólo de una parte de éste, la plebe, ejerció durante la República romana un papel absolutamente principal, sobre todo a partir del 286

\footnotetext{
${ }^{63}$ Vide nota 5 para la bibliografía sobre las distintas instituciones jurídico-políticas de la República romana.
} 


\section{REVISTA VIRTUAL VIA INVENIENIDI ET IUDICANIDI}

"CAMINO DEL HALLAZGO Y DEL JUICIO"

http://viei.usta.edu.co/E-MAIL: revistainveniendi@usantotomas.edu.co

a.C. fecha en que la aprobación de la lex Hortensia determinó la equiparación de los plebiscitos a las leges publicae ${ }^{64}$ y que, unido a la reforma de los comitia centuriata en el 241 a.C., "muestran la tendencia de la asamblea ciudadana hacia formas más democráticas" (Torrent, 2002, pág. 215). Esto, evidentemente, va unido a la concepción que del populus - o dêmos- se tuvo en una u otra civilización, y así, mientras que en Atenas el término dêmos designa a veces al todo el pueblo ateniense pero en otras, según avanza la democracia, al "pueblo como sector de la población, orgullosa fuente de poder" o "el pueblo como clase" (Rodríguez Adrados, 1997, pág. 82 y 98), en Roma, la terminología, sobre todo hasta mediados de la república, impone el populus y la plebs como dos realidades diferentes aunque técnicamente incluída la segunda en la primera ${ }^{65}$ : populus como elemento de la constitución republicana ${ }^{66}$ y la plebs como un sector de ese populus -distinto originariamente del patriciado- que pronto ${ }^{67}$ tomó "conciencia de clase" y asumió la dirección para la equiparación política con el patriciado, sobre todo aquel sector de la plebe que tenía una cierta autonomía económica (de

\footnotetext{
${ }^{64}$ Con la aprobación -auctoritas patrum- si bien preventiva del Senado.

${ }^{65}$ No debemos tomar, desde mi punto de vista, estas afirmaciones de manera categórica puesto que dependen del momento concreto de la historia de Roma en la que nos encontremos (etapa arcaica, principios de la república o época de esplendor repubicano). Vide ampliamente, sobre identificación de populus y plebs en la roma arcaica (Magdelain, 1990).

${ }^{66}$ Incluso, a mi juicio, desde la época monárquica, aunque su participación fuera testimonial, sin capacidad deliberante y no representativa, más como ciudadanos-soldados frente al jefe de la urbs-jefe militar, como se aprecia en su participación en la ceremonia jurídico-religiosa de la aprobación de la primitiva lex curiata de imperio. Para de Martino (1973, pág. 158 T.I) este es el momento en el que el pueblo se convierte en órgano de la constitución por primera vez.

${ }^{67}$ Con el "pronto" me refiero a partir de la cesura temporal que marca el inicio de la República tras la caída de la monarquía en el 509 a.C. y que podemos situar en el 494 a.C. fecha en la que la tradición romana fija la creación del tribuno de la plebe. A partir del 471 a.C. la elección de los tribunos se extendería a un sector mayor dentro de la plebe con lo que tanto el magistrado plebeyo, el tribuno, como la asamblea plebeya, los concilia plebis tributa, quedaría reafirmados dentro de la estructura constitucional romana.
} 


\section{REVISTA VIRTUAL VIA INVENIENDI ET IUDICANDI}

"CAMINO DEL HALLAZGO Y DEL JUICIO"

http://viei.usta.edu.co/E-MAIL: revistainveniendi@usantotomas.edu.co

Martino, 1973). El hecho de tener una asamblea y magistrados propios ha coadyuvado a esta contraposición; sin embargo, como ha señalado Torrent (2002, pág. 191 y ss.) populus y plebs quedan integrados en la evolución constitucional romana, fundamentalmente porque no tiene un valor inmutable ni absoluto.

Cicerón al definir la república como "lo que pertenece al pueblo" nos da las notas características de lo que el pueblo es, desde luego, lo que era el populus romanus empezando por el opuesto: "pueblo no es todo conjunto de hombres reunidos de cualquier manera, sino el conjunto de una multitud asociada por un mismo derecho que sirve a todos por igual” (de rep. I, 25,39). La definición enlaza con la idea que rescatábamos como hilo conductor en la República desde su nacimiento: la libertas. Decíamos que era la única palabra, junto con re publica que encontrábamos para definirla, hasta el punto de que parecen sinónimas. La re publica pertenece al populus y el ius, el derecho, es el que otorga al populus su condición de tal, es decir de comunidad organizada porque, además, es el que garantiza la libertas que hizo nacer la república y que la mantuvo; por eso tienen razón los autores que encuadran la libertas dentro del ordenamiento jurídico romano, como sumisión voluntaria a la ley votada en común (Gaudemet, 1994, pág. 357) y que pone de manifiesto "el sentido intrínsecamente jurídico de la noción de la libertas romana" (de Andrés Santos, 2005, pág. 16) y que no sólo queda reflejada en el ámbito del derecho público, sino también en el derecho privado y así fue recogida por los juristas republicanos y clásicos (de Andrés 


\section{REVISTA VIRTUAL VIA INVENIENDI ET IUDICANDI}

"CAMINO DEL HALLAZGO Y DEL JUICIO"

http://viei.usta.edu.co/ E-MAIL: revistainveniendi@usantotomas.edu.co

Santos, 2005) con un auténtico sistema de garantías en todos los ámbitos de la vida de un ciudadano (Herrera Bravo, 2002).

Pero en Roma, como señala Torrent, (2002, pág. 234) el populus que se concibe como el conjunto de los ciudadanos libres también significa una cierta personificación del Estado con lo que incluiría a los demás órganos constitucionales.

Esto me lleva al segundo aspecto al que antes me he referido: el hecho de que el planteamiento del esquema democrático-constitucional sea diferente en Roma y en Atenas llevado, sin duda, porque sus historias son diferentes y también probablemente porque los estudiosos en la materia tendamos a contraponer, para comparar sus sistemas democráticos, las dos ciudades en momentos evolutivos diferentes. Y así, en Atenas tomamos la historia de la democracia desde el que se considera su inicio -Solón- y en cambio en la Roma republicana partimos del momento en el que las instituciones jurídico-políticas que integran la constitución republicana están ya consolidadas. Por eso también quizá, cuando analizamos Atenas frente a Roma, en la primera nos estamos fijando en sus personajes protagonistas: Solón, Clístenes, Efialtes, Pericles, mientras que en la segunda la ciuitas es la protagonista, la re publica y los órganos constitucionales que lo forman. Esto no significa que no haya habido reformas democráticas en Roma cuya autoría se atribuya a personas concretas pero no ha quedado en la memoria 


\section{REVISTA VIRTUAL VIA INVENIENDI ET IUDICANDI}

"CAMINO DEL HALLAZGO Y DEL JUICIO"

http://viei.usta.edu.co/E-MAIL: revistainveniendi@usantotomas.edu.co

unos "padres fundadores de la república". Por ello, mientras que en Atenas el equilibrio de los órdenes al que nos hemos referido era un equilibrio entre posibles formas de gobierno, expresadas de manera más o menos clara en las distintas instituciones que componían la constitución ateniense, equilibrio que si se rompía podía acabar en la stásis, en la república Roma no existió el equilibrio entre órdenes sino un equilibrio entre órganos constitucionales a los que la plebe luchó para acceder -y lo consiguió- en igualdad con el patriciado.

Por ello quizá, el camino de Atenas hacia la democracia fue más revolucionario que la andadura de la re publica romana. Cuando Aristóteles dice en su Política que "hay un principio común a todos los regímenes políticos: la parte de la polis que desee una determinada constitución tiene que se más poderosa que la que no lo desee" $(1296$ b,14) refleja lo que pasó en Atenas: dos -o más-

formas de gobierno en lucha por la constitución que deseaban, mientras que en la república romana lo que hubo fue una lucha por parte de un amplísimo sector del populus, -la plebe, nervio de la sociedad romana (de Martino, 1973, pág. 349 T I)de integrarse en la estructura de la constitución republicana existente.

\section{3.- Conclusiones.}

Hemos podido ver a lo largo de las páginas anteriores cómo Atenas y Roma estructuran un orden constitucional que permitió un desarrollo de principios 


\section{REVISTA VIRTUAL VIA INVENIENDI ET IUDICANDI}

"CAMINO DEL HALLAZGO Y DEL JUICIO"

http://viei.usta.edu.co/ E-MAIL: revistainveniendi@usantotomas.edu.co

democráticos aplicados a la praxis política que permiten decir que estamos ante dos civilizaciones y dos momentos de la Historia de la Humanidad en los que el conjunto del pueblo, como conjunto de ciudadanos, se integra como uno de los elementos que conforman dicho orden constitucional.

En el mundo antiguo, quizá más que separación de poderes tal y como la concebimos en la actualidad existió un reparto de poderes del cual participó el pueblo junto con el Senado y las magistraturas en Roma, o con el Areópago y arcontado en Atenas y que se distinguió por la lucha constante del elemento popular en ir restando poder efectivo a los órganos que, originariamente, representaban a las clases poderosas; dicho de otra manera, la lucha se dirigió a que los órganos constitucionales estuvieran lo más participados posible por el pueblo.

A mi juicio, Atenas llegó más lejos en este propósito también como hemos dicho porque el planteamiento histórico del inicio de la democracia fue distinto. La democracia en Atenas más que el "poder del pueblo" -dêmos y kratos- fue la prevalencia del pueblo frente a otros órganos de poder que también intervienen en la esfera político-gubernamental en relación de más o menos igualdad con el pueblo, casi siempre en lucha, según los momentos históricos a los que nos asomemos. 


\section{REVISTA VIRTUAL VIA INVENIENDI ET IUDICANDI}

"CAMINO DEL HALLAZGO Y DEL JUICIO"

http://viei.usta.edu.co/ E-MAIL: revistainveniendi@usantotomas.edu.co

En Roma, los principios democráticos que se fueron incorporando a la constitución republicana hacen de ella un sistema que aspira "a la libertas como hálito democrático constante" (Torrent, 2002, pág. 238) lo que merece ser tenido en cuenta de forma notable. La libertas, ya lo hemos dicho, como sometimiento a la ley de todos; el derecho como ligamen de la sociedad unida para la consecución de un fin común; este aspecto quizá también sea más notable en Roma que en Atenas: el sometimiento a la ley como marco jurídico general, sometimiento también del populus. Señala Ribas muy acertadamente, que la libertas romana "es la que corresponde a la del denominado Estado de Derecho: sometida a la ley y, por lo tanto, limitada (2008, pág. 15) ${ }^{68}$.

Quizá el sentido práctico de los romanos, que sabía bien los problemas a los que llevaban las formas degeneradas de los distintos sistemas de gobierno y lo fácil que era para una sociedad caer en ellas, lleva a decir a Cicerón, por boca de Escipión "no apruebo ninguna de ellas <de las formas de gobierno clásicas> por separado, y doy preferencia a aquella otra en la que se refunden todas" (de rep., I, $35,54)$.

\footnotetext{
${ }^{68}$ Vide también su reciente Libertad, la vía romana hacia la democracia, Comares, Granada, 2009.
} 


\section{REVISTA VIRTUAL VIA INVENIENIDI ET IUDICANIDI}

"CAMINO DEL HALLAZGO Y DEL JUICIO"

http://viei.usta.edu.co/E-MAIL: revistainveniendi@usantotomas.edu.co

REFERENCIAS BIBLIOGRÁFICAS:

- Arangio-Ruiz, V. (1980). Historia del derecho romano (4⿳亠丷厂 ed.). Madrid. Reus.

- Aristóteles. Constitución de los Atenienses. (M. G. Valdés, Trad.) Gredos, 1984.

- Branca, G. (1960). "Democrazia politica e reppublica romana" en Conferenze Romanistiche (págs. 201-222). Milán. Giuffrè.

- Catalano, P. (1962). "Il principio democratico". Studia et Documenta Historiae et luris , 316-329.

- Cicerón, sobre la república (A. D’Ors, Trad.) Gredos, 1991.

- Crifò, G. (2000). Civis. La cittadinanza tra antico e moderno. Roma-Bari. Laterza.

- de Andrés Santos, F. J. (2005). "Consideraciones en torno a la aportación del Derecho romano a la filosofía política republicana". Revista General de Derecho Romano (junio, 4) (www.iustel.es).

- de Martino, F. (1973). Storia della costituzione romana. Nápoles. Jovene.

- Ehrenberg, V. (1969). The Greek State. Londres.

- Finley, M. I. (1990). Estudios sobre historia antigua. Madrid. Akal.

- Finley, M. I. (1987). La Grecia primitiva: edad de bronce y era arcaica. (T. Sempere, Trad.) Barcelona. Crítica.

- Finley, M. I. (1977). Uso y abuso de la historia. Barcelona. Crítica. 


\section{REVISTA VIRTUAL VIA INVENIENDI ET IUDICANDI}

"CAMINO DEL HALLAZGO Y DEL JUICIO"

http://viei.usta.edu.co/ E-MAIL: revistainveniendi@usantotomas.edu.co

- Gaudemet. (1994). Les institutions de l'antiquité. París. Montchrestien

- Gil, L. (1989). "La ideología de la democracia ateniense" en Cuadernos de Filología Clásica, № 23, Madrid

- Gil, L. (1996) "Sobre la raigambre griega del sistema democrático", en Cuadernos de Filología Clásica (Estudios griegoe e indoeuropeos), ํㅡ 6, UCM, pp. 11-21.

- Herrera Bravo, R. (2002). "Las instituciones democráticas en la República Romana y su proyección histórico-política" en, La democracia a debate (págs. 101-108). Dykinson

- Heródoto, Historia. Las guerras médicas, (C. Schrader, trad.), Gredos, 1989.

- Hignett, C. (1952). A History of the Athenian Constitution. Oxford.

- Livio, Historia de Roma desde su fundación. (J. A. Villar Vidal, Trad.) Gredos, 1990.

- López Melero, R. (1989). La formación de la democracia ateniense II. De Solón a Clístenes. Madrid: Akal.

- Lucca, J. B. (2006). "Vicisitudes e itinerarios de los conceptos. Peripecias del control del demos y eventualidades de la accountability del kratos". Temas y debate , 10 (12), 66-96.

- Magdelain, A. (1990). "La plèbe et la noblesse dans la Rome archäique" en Jus Imperium Auctoritas. Études de droit romain (242-295). Roma. École FranÇaise de Rome. 


\section{REVISTA VIRTUAL VIA INVENIENDI ET IUDICANDI}

"CAMINO DEL HALLAZGO Y DEL JUICIO"

http://viei.usta.edu.co/ E-MAIL: revistainveniendi@usantotomas.edu.co

- Maíz, R. (2006). "Deliberación e in clusión en la democracia republicana" Reis: Revista española de investigaciones sociológicas, 11-47.

- Mossé, C. (2004). "How a political myth takes shape: Solon, "founding father" of the Athenian Democracy", en Athenian Democracy (págs. 242259). Edimburgo. Edimburg University Press.

- Ober, J. (2004). "The Athenian Revolution of 508/7 B.C: Violence, Authority, and the Origins of Democracy", en Athenian Democracy (págs. 260-286). Edimburgo. Edimburgh University Press.

- Plácido Suárez, D. (2007). "Las formas del poder personal: la monarquía, la realeza y la tiranía". Gerión , 25 (1), 127-166.

- Plácido Suarez, D. (1989). "Tucídides, sobre la tiranía". Gerión, (Ejemplar dedicado a: Estudios sobre la Antigüedad en Homenaje al profesor Santiago Montero Díaz) (2 extra), 155-164.

- Plutarco, Vidas Paralelas. Solón-Publícola. (A. R. Romanillos, Trad.) Buenos Aires: Austral, 1948

- Rhodes, P.J. (2004) ed. Athenian Democracy, Edimburgo, Edimburgh University Press.

- Ribas Alba, J.M. (2008) Democracia en Roma. Introducción al Derecho Electoral Romano, Granada, Comares.

- Ribas Alba, J.M. (2009). Libertad. La vía romana hacia la democracia, Granada, Comares. 


\section{REVISTA VIRTUAL VIA INVENIENDI ET IUDICANDI}

"CAMINO DEL HALLAZGO Y DEL JUICIO"

http://viei.usta.edu.co/E-MAIL: revistainveniendi@usantotomas.edu.co

- Rodríguez Adrados, F. (1997). Historia de la democracia. De Solón a nuestros días. Madrid. Temas de Hoy.

- Rotondi, G. (1990). Leges publicae populi romani (facsimil de la edición de 1912 ed.). Hildesheim-Zürich-New HYork. Olms.

- Salerno, F. (1999). "Tacita libertas". L'introduzione del voto segreto nella Roma repubblicana. Nápoles. Edizioni Scientifiche Italiane.

- Sánchez de la Torre, A. (1996). "Procesos de participación política en la República romana: reflexiones entre Tito Livio y Maquiavelo", en Seminarios Complutenses de Derecho Romano: revista complutense de Derecho Romano y tradición romanística, № 8, pp.233.274.

- Sancho Rocher, L. (2005). "¿Qué tipo de decmocracia? La politeia ateniense entre 403 y 322 a.C." Studia Historica: Historia Antigua (23), 177229.

- Sartori, G. (2007). ¿Qué es la democracia? Madrid. Taurus.

- Sartori, G. (2009). La democracia en 30 lecciones. Madrid. Taurus.

- Sartori, G. (1988). Teoría de la democracia. 1. El debate contemporáneo. Madrid. Alianza editorial.

- Sartori, G. (1988). Teoría de la Democracia. 2. Los problemas clásicos. Madrid. Alianza editorial.

- Sousa. (2005). "Contribuçao para uma história das interpretaçoes de Heródoto", III.80-82. Humanitas (57), 117-132. 


\section{REVISTA VIRTUAL VIA INVENIENIDI ET IUDICANIDI}

"CAMINO DEL HALLAZGO Y DEL JUICIO"

http://viei.usta.edu.co/E-MAIL: revistainveniendi@usantotomas.edu.co

- Torrent. (2002). Derecho Público Romano y Sistema de Fuentes. Zaragoza. Edisofer.

- Torrent Ruiz, A. (2005). Diccionario de Derecho Romano. Madrid. Edisofer.

- Torrent Ruiz, A. (2007). "Moneda, crédito y derecho penal monetario en Roma (s. IV a.C.-IV d.C)". Studia et Documenta Historiae et luris (LXXIII), 111-158.

- Valmaña Ochaíta, A. (1998). Apio Claudio. Madrid. Ediciones Clásicas.

- Valmaña Ochaíta, A. (1995). Las reformas políticas del censor Apio Claudio Ciego. Murcia. Servicio de publicaciones de la Universidad de Castilla-La Mancha.

- Vidal-Naquet, P. (1992). La demcoracia griega, una nueva visión. Madrid: Akal. 